\title{
Passive or Active Immunization with Myelin Basic Protein Promotes Recovery from Spinal Cord Contusion
}

\author{
Ehud Hauben, ${ }^{1}$ Oleg Butovsky, ${ }^{1}$ Uri Nevo, ${ }^{1,4}$ Eti Yoles, ${ }^{1}$ Gila Moalem, ${ }^{1,2}$ Eugenia Agranov, ${ }^{5}$ Felix Mor, ${ }^{2}$ \\ Raya Leibowitz-Amit, ${ }^{1}$ Evgenie Pevsner, ${ }^{6}$ Solange Akselrod, ${ }^{4}$ Michal Neeman, ${ }^{3}$ Irun R. Cohen, ${ }^{2}$ and \\ Michal Schwartz ${ }^{1}$
}

\author{
Departments of ${ }^{1}$ Neurobiology, ${ }^{2} /$ mmunology, and ${ }^{3}$ Biological Regulation, The Weizmann Institute of Science, Rehovot \\ 76100, Israel, ${ }^{4}$ Department of Medical Physics, Tel-Aviv University, Tel-Aviv 69978, Israel, ${ }^{5}$ Beit Levinstein Hospital, \\ Raanana 43100, Israel, and ${ }^{6}$ Department of Neurosurgery, Sheba Medical Center, Tel-Aviv University, Tel-Aviv 52621, Israel
}

Partial injury to the spinal cord can propagate itself, sometimes leading to paralysis attributable to degeneration of initially undamaged neurons. We demonstrated recently that autoimmune $T$ cells directed against the CNS antigen myelin basic protein (MBP) reduce degeneration after optic nerve crush injury in rats. Here we show that not only transfer of $\mathrm{T}$ cells but also active immunization with MBP promotes recovery from spinal cord injury. Anesthetized adult Lewis rats subjected to spinal cord contusion at T7 or T9, using the New York University impactor, were injected systemically with anti-MBP $\mathrm{T}$ cells at the time of contusion or 1 week later. Another group of rats was immunized, 1 week before contusion, with MBP emulsified in incomplete Freund's adjuvant (IFA). Functional recovery was assessed in a randomized, double-blinded manner, using the open-field behavioral test of Basso, Beattie, and Bresnahan. The functional outcome of contusion at T7 differed from that at T9 $(2.9 \pm 0.4, n=$ 25 , compared with $8.3 \pm 0.4, n=12 ; p<0.003$ ). In both cases, a single $\mathrm{T}$ cell treatment resulted in significantly better recovery than that observed in control rats treated with $\mathrm{T}$ cells directed against the nonself antigen ovalbumin. Delayed treatment with $T$ cells ( 1 week after contusion) resulted in significantly better recovery $(7.0 \pm 1 ; n=6)$ than that observed in control rats treated with PBS (2.0 $\pm 0.8 ; n=6 ; p<0.01$; nonparametric ANOVA). Rats immunized with MBP obtained a recovery score of $6.1 \pm 0.8$ $(n=6)$ compared with a score of $3.0 \pm 0.8(n=5 ; p<0.05)$ in control rats injected with PBS in IFA. Morphometric analysis, immunohistochemical staining, and diffusion anisotropy magnetic resonance imaging showed that the behavioral outcome was correlated with tissue preservation. The results suggest that $T$ cell-mediated immune activity, achieved by either adoptive transfer or active immunization, enhances recovery from spinal cord injury by conferring effective neuroprotection. The autoimmune $T$ cells, once reactivated at the lesion site through recognition of their specific antigen, are a potential source of various protective factors whose production is locally regulated.

Key words: CNS; beneficial autoimmunity; myelin basic protein; neurofilaments; spinal cord injury; secondary degeneration; neuroprotection; $E A E$
Injury to the mammalian CNS often results in an irreversible functional deficit (Kalb, 1995; Schwab and Bartholdi, 1996) for several reasons, including lack of neurogenesis (formation of new cell bodies), the poor ability of injured axons to regrow, and a destructive series of injury-induced events that result in the lateral and longitudinal spread of damage to neurons that escaped the direct injury (Faden, 1993; Povlishock and Jenkins, 1995; Yoles and Schwartz, 1998). This spread of damage is termed secondary degeneration.

Attempts to promote CNS recovery have focused on two goals: (1) the stimulation of regeneration (Caroni and Schwab, 1988; Reier et al., 1992; Cheng et al., 1996; Davies et al., 1997; Li et al., 1997; Miya et al., 1997; Rapalino et al., 1998; Wang et al., 1998; Chong et al., 1999; Neumann and Woolf, 1999), and (2) neuroprotection, or the arrest of secondary degeneration (Behrmann et al., 1994; Constantini and Young, 1994; Sanner et al., 1994; Basso et al., 1996; Gruner et al., 1996; Beattie et al., 1997; Crowe et al., 1997; Bethea et al., 1998; Yong et al., 1998; Bavetta et al., 1999; Moalem et al., 1999; Schwartz et al., 1999). Attempts have also been made to improve the functional outcome of surviving neurons (Blight, 1989).

Spinal cord lesions, regardless of the severity of the injury,

Received March 20, 2000; revised June 14, 2000; accepted June 14, 2000.

The work was supported in part by a grant from the Alan Brown Foundation for Spinal Cord Injury (awarded to M.S.). We thank Shirley Smith for editing the manuscript. I.R.C. is the incumbent of the Mauerberger Chair in Immunology, and M.S. holds the Maurice and Ilse Katz Professorial Chair in Neuroimmunology.

Correspondence should be addressed to M. Schwartz, Department of Neurobiology,

The Weizmann Institute of Science, 76100 Rehovot, Israel. E-mail: michal.schwartz@ weizmann.ac.il.

Copyright (C) 2000 Society for Neuroscience $0270-6474 / 00 / 206421-10 \$ 15.00 / 0$ initially result in complete functional paralysis (Basso et al., 1995, 1996; Young, 1996). Some spontaneous recovery may be observed, starting a few days after the injury and tapering off within 3-4 weeks; the less severe the insult, the better the functional outcome (Young, 1996). The extent of recovery, in the absence of regeneration or any intervention leading to neuroprotection, is a function of the amount of tissue that escaped the initial injury minus the neuronal loss attributable to secondary degeneration. It follows that recovery would be improved by neuroprotective treatment that could contribute to the rescue of initially undamaged or marginally damaged fibers from secondary degeneration.

Studies during the past decade have demonstrated some plasticity of the injured spinal cord and have shown that the use of compounds capable of mitigating the toxic effects of biochemical mediators of secondary degeneration offers a promising new approach to neuroprotective therapy. Glutamate receptor antagonists, for example, can reduce the tissue damage resulting from an injury-induced increase in glutamate, an excitatory amino acid that normally acts as a physiological transmitter but is toxic at high concentrations (Panter et al., 1990). Another example is the use of neurotrophic compounds, which provide neuroprotection by preventing nerve atrophy (Blesch and Tuszynski, 1997; Bregman et al., 1998; Houweling et al., 1998; Franzen et al., 1999; Houle and Ye, 1999; Rabchevsky et al., 1999).

The present study of spinal cord neuroprotection in the rat was prompted by our recent finding that partial injury to the rat optic nerve can be mitigated by administering T cells specific to a CNS self-antigen, myelin basic protein (MBP) (Moalem et al., 1999), and by our preliminary observation that these autoimmune $\mathrm{T}$ cells also promote behavioral recovery after severe contusion of the 
adult rat spinal cord (Hauben et al., 2000). We have shown previously that the neuroprotective effect of the autoimmune $\mathrm{T}$ cells is mediated, at least in part, by neurotrophic factors, the secretion of which is antigen-dependent (G. Moalem, A. Gdalyahu, Y. Shani, U. Otten, P. Lazarovici, I. R. Cohen, and M. Schwartz, unpublished observations). Thus, systemic injection of activated autoimmune $\mathrm{T}$ cells appears to be a feasible cell therapy that offers some advantages. First, these T cells can cross the blood-brain barrier (Hickey et al., 1991) and specifically accumulate at the site of a CNS lesion (Hirschberg et al., 1998). Second, the T cells are capable of continuously releasing various factors at the lesion site as a result of their reactivation at the lesion site upon encountering their antigen. The timing and dynamics of such release might be in accordance with the needs of the tissue. Here we examined neuroprotective efficacy as a function of the severity of spinal cord injury and the time lapse after the injury. We also examined whether adoptive transfer of T cells for therapeutic purposes can be replaced by active immunization. The behavioral outcome in the treated rats was examined in relation to the results of morphological and imaging analyses.

\section{MATERIALS AND METHODS}

Animals. Inbred female adult Lewis rats (10-12 weeks old, 200-250 gm) were supplied by the Animal Breeding Center of the Weizmann Institute of Science. The rats were housed in a light- and temperature-controlled room and matched for age in each experiment.

Antigens. MBP was prepared from the spinal cords of guinea pigs (Moalem et al., 1999) or purchased from Sigma (St. Louis, MO). Ovalbumin (OVA) was purchased from Sigma.

Spinal cord contusion. Rats were anesthetized, and the spinal cord was exposed by laminectomy at the level of T7 or T9. One hour after induction of anesthesia, a $10 \mathrm{gm}$ rod was dropped onto the laminectomized cord from a height of $50 \mathrm{~mm}$, using the New York University impactor (Basso et al., 1996; Young, 1996). Sham-operated female Lewis rats were laminectomized but not contused.

Passive or active immunization. Within $1 \mathrm{hr}$ of contusion or 1 week later, the rats were injected intraperitoneally, on a random basis, with $10^{7} \mathrm{~T}$ cells (specific to either MBP or the foreign antigen OVA) or PBS. In another experiment, rats had been actively immunized (subcutaneously), 1 week before contusion, with MBP or PBS emulsified in incomplete Freund's adjuvant (IFA). Sham-operated (laminectomized but not contused) rats in each experiment received $10^{7}$ anti-MBP $\mathrm{T}$ cells or immunization with MBP in IFA. These rats were examined daily for the severity of the disease that they developed and scored on a scale of 1 to 5 (Ben Nun and Cohen, $1982 \mathrm{a}, \mathrm{b})$

In the contused rats, bladder expression was performed manually at least twice a day (particularly during the first $48 \mathrm{hr}$ after injury, when it was done up to three times a day), until the end of the second week, by which time automatic voidance had been recovered. The rats were carefully monitored for evidence of urinary tract infection or any other sign of systemic disease. During the first week after contusion and in any case of hematuria after this period, they received a course of sulfamethoxazole $(400 \mathrm{mg} / \mathrm{ml})$ and trimethoprim ( $8 \mathrm{mg} / \mathrm{ml}$ ) (Resprim; Teva Pharmaceutical Industries, Petach Tikva, Israel), administered per os with a tuberculin syringe $(0.3 \mathrm{ml}$ of solution per day). Daily inspections included examination of the laminectomy site for evidence of infection and assessment of the hind limbs for signs of autophagia or pressure.

Assessment of recovery from spinal cord contusion. Behavioral recovery was scored on a scale of 0 (complete paralysis) to 21 (complete mobility) (Behrmann et al., 1994; Basso et al., 1995, 1996) by observers blinded to the treatment received by each rat. Approximately twice a week, the locomotor activities of the trunk, tail, and hind limbs were evaluated in an open field by placing each rat for $4 \mathrm{~min}$ in the center of a circular enclosure made of molded plastic with a smooth, nonslip floor $(90 \mathrm{~cm}$ diameter, $7 \mathrm{~cm}$ wall height). Before each evaluation, we carefully examined the rats for perineal infection, wounds in the hind limbs, or tail and foot autophagia.

$T$ cell lines. T cell lines were generated from draining lymph node cells obtained from Lewis rats immunized with the above antigens, as described previously (Ben Nun and Cohen, 1982a,b). Propagation and restimulation of the cells were performed as was previously described previously by us (Moalem et al., 1999).

Retrograde labeling of rubrospinal neurons. Two or three months after spinal contusion followed immediately by immunization with anti-MBP T cells or treatment with PBS, three rats from each group were reanesthetized, and the dye rhodamine dextran amine (Fluoro-ruby; Molecular Probes, Eugene, OR) (Brandt and Apkarian, 1992) was applied below the site of contusion at T12. The number of dye-stained cells counted in the red nuclei of the brain was taken to represent the number of intact axons descending from the red nucleus and traversing the area of contusion (Strominger et al., 1987). After $5 \mathrm{~d}$, the rats were again deeply anesthetized, and their brains were excised, processed, and cryosectioned. All sections (40 $\mu \mathrm{m}$ each) taken through the entire red nucleus of each brain were analyzed qualitatively and quantitatively by fluorescence and confocal microscopy. The total numbers of labeled cells were counted in each section and in all sections from each brain. Thus, the number of labeled cells recorded for each brain is the sum of all the cells counted in each section. The number of labeled neurons in each rat is given by the average number of cells counted in its two red nuclei. In the statistical analysis, we used a corrective factor to allow for the thickness of the sections and the size of a single nucleus so as to correct for possible recounting of the same cell (Smolen et al., 1983; Sanner et al., 1994).

Immunohistochemistry. Each rat was perf used intracardially with $100 \mathrm{ml}$ (on average) of cold PBS, followed by $200 \mathrm{ml}$ of paraformaldehyde (4\% prepared in $0.1 \mathrm{M}$ phosphate buffer with glucose $5 \%$ ). Spinal cords were removed, post-fixed overnight, briefly rinsed in PBS, and transferred to $30 \%$ sucrose for cryoprotection for at least $3 \mathrm{~d}$. All procedures were performed at $4^{\circ} \mathrm{C}$. A $30 \mathrm{~mm}$ section of the spinal cord, with the injury site at the center, was excised, embedded in Tissue-Tec (Miles, Elkhart, IN), and placed in liquid nitrogen. Frozen longitudinal $20 \mu \mathrm{m}$ sections were obtained with a cryostat, collected onto gelatin-coated slides, and dried at room temperature. Sections were fixed in absolute ethanol for $10 \mathrm{~min}$ at room temperature, washed twice in double-distilled water, and incubated for 3 min with $0.5 \%$ Tween 20 (Sigma) in PBS to increase the permeability of the tissue. Antibodies against rat glial fibrillary acid protein (GFAP) (diluted 1:100; NeoMarkers, Fremont, CA) or against neurofilaments (NF) (v/v mixture of 68 and $200 \mathrm{kDa}$ NFs, diluted 1:50; Novocastra Laboratories, Newcastle upon Tyne, UK) were applied to sections for $1 \mathrm{hr}$ at room temperature in a humidified chamber. Sections were rinsed three times with Tris-buffered saline $(0.05 \%$ Tween 20 in PBS) and then incubated with fluorescein-conjugated secondary antibodies (Alexa-488 or Alexa546, diluted 1:200; Molecular Probes, Eugene, OR) for $1 \mathrm{hr}$ at room temperature. They were then washed well and treated for $8 \mathrm{~min}$ with a solution of $0.3 \%$ Sudan black B (Merck, Darmstadt, Germany) in $70 \%$ ethanol to reduce or eliminate the autofluorescence. If overstained, the sections were dipped in clean $70 \%$ ethanol until staining was satisfactory. They were then mounted with anti-fading oil and coverslips and examined by confocal laser scanning fluorescence microscopy. The results were analyzed by an observer who was blinded to the identity of the rats.

Diff usion-anisotropy magnetic resonance imaging. Diff usion anisotropy of spinal cords from anti-MBP T cell-treated rats and PBS-treated controls was measured in a Bruker DMX 400 wide-bore spectrometer, using a microscopy probe with a $5 \mathrm{~mm}$ Helmholz coil and actively shielded magnetic field gradients. The observer was blinded to the treatment received by the rats. Multislice echo imaging was performed with nine axial slices, with the central slice positioned at the center of the spinal injury. Images were obtained with an echo time of $31 \mathrm{msec}$, a repetition time of $2000 \mathrm{msec}$, a diff usion time of $15 \mathrm{msec}$, a diff usion gradient duration of $3 \mathrm{msec}$, a field of view of $0.6 \mathrm{~mm}$, matrix size of $128 \times 128$ pixels, slice thickness of 0.5 $\mathrm{mm}$, and slice separation of $1.18 \mathrm{~mm}$. Left to right images represent axial sections from head to foot. Four diff usion gradient values $(0,28,49$, and 71 $\mathrm{gm} / \mathrm{cm}$ ) were applied along the read direction (transverse diffusion) or along the slice direction (longitudinal diffusion). Using an exponential fit for each pixel, we obtained a transverse and a longitudinal apparent diffusion coefficient map, from which an anisotropy ratio matrix was derived. The accumulated anisotropy in each slice was integrated (Nevo et al., 2000). For each rat, the lowest value of the slice anisotropy integral was defined as the lesion site.

\section{RESULTS}

\section{Passive immunization promotes recovery from spinal cord contusion}

Using the Basso, Beattie, and Bresnahan (BBB) open-field locomotor test, we first assessed the behavioral outcome of a contusion injury caused by dropping of a uniform weight from the same height onto the laminectomized spinal cord at two levels, T7 and T9. The functional deficit, examined in randomly selected rats by an observer blinded to the treatment they had received, was significantly greater after contusion at the level of T7 (BBB score of $2.9 \pm 0.8$; $n=25)$ than at T9 (BBB score of $8.4 \pm 0.6 ; n=12 ; p<0.003$; ANOVA) (Fig. 1).

Our preliminary results (Hauben et al., 2000) suggested that systemic injection, immediately after contusion at T7, of autoimmune $\mathrm{T}$ cells specific to MBP promotes recovery of locomotor activity in rats. No effect was observed in rats that were similarly injected with $\mathrm{T}$ cells specific to the nonself antigen OVA (Hauben et al., 2000). Here we examined whether this beneficial T cell effect could also be demonstrated after the less severe contusion at T9 and in the most severe case of complete axotomy.

Anesthetized rats were subjected to contusion at the level of T9. Six rats were then injected intraperitoneally with autoimmune $\mathrm{T}$ cells specific to MBP (Ben Nun et al., 1981; Mor and Cohen, 1992) (anti-MBP T cell-treated group), whereas six others (controls) 


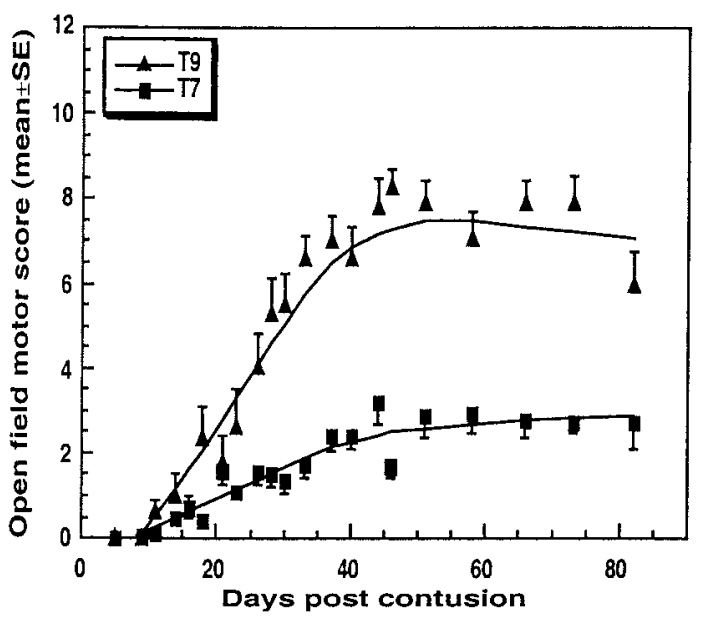

Figure 1. Spontaneous recovery from spinal cord contusion at T7 and T9. Rats were subjected to spinal cord contusion under deep anesthesia and immediately injected systemically with PBS. Recovery was assessed by the BBB open-field test at the indicated time points by observers blinded to the treatment received by the rats. Results are expressed as the mean values for each group (error bars indicate SEM). The differences, tested by repeated ANOVA, were significant (T7, $n=25$; T9, $n=12 ; p<0.003$ ).

received PBS without $\mathrm{T}$ cells. Three age-matched, sham-operated rats were injected with autoimmune $\mathrm{T}$ cells specific to $\mathrm{MBP}$. Behavioral recovery was assessed using the BBB test. During the first few days, none of the rats with contused spinal cords showed any locomotor activity (Fig. $2 A$ ). Interestingly, however, the rats treated with the anti-MBP T cells showed signs of recovery earlier than any of the PBS-treated controls. On day 11, when no recovery could be detected in the controls, significant improvement was noted in the anti-MBP $\mathrm{T}$ cell-treated group. At all time points thereafter, the latter group showed significantly greater locomotor recovery than the controls (Fig. $2 A$ ). It should be emphasized that any earlier positive effect that the anti-MBP T cells might have had on the injured spinal cord would have been masked by the transient paralytic effect of these encephalitic $\mathrm{T}$ cells (Fig. 2B). Thus, the autoimmune $\mathrm{T}$ cells, despite being encephalitic, promoted recovery that was detectable as soon as the disease resolved itself.

By 1 month after injury, the rats in both the PBS-treated and the $\mathrm{T}$ cell-treated groups had reached a maximal behavioral score, which then remained at a plateau for at least 5 months of follow-up. In PBS-treated control rats, the maximal locomotor recovery was marked by some ineffectual movements of all hindlimb joints, and most of these rats could not support their weight. Their average \pm SEM locomotor score was $7.3 \pm 0.8$. In contrast, the average score of similarly contused rats (T9) treated with anti-MBP T cells was $10.2 \pm 0.8$. These rats could support their body weight, and some could walk in a coordinated manner. The difference between the two groups (T9 contusion with and without T cells), based on two-factor repeated ANOVA, was significant $(p<0.05)$. No recovery after treatment with anti-MBP $\mathrm{T}$ cells was detected in rats with completely transected spinal cords (Fig. 2C). These findings suggest that the effect of the anti-MBP T cells is primarily neuroprotective, i.e., nerve fibers that escaped the primary injury are protected from secondary degeneration. After complete transection in which no fibers were spared, the $\mathrm{T}$ cell treatment had no effect. Thus, within the time frame of the experiments described here, the beneficial effect of the anti-MBP T cells could be attributed to neuroprotection of neurons that apparently escaped the primary lesion.

In all cases, the activity of the autoimmune $T$ cells was verified by injecting three or four sham-operated rats with the anti-MBP T cells and examining the rats daily (Fig. $2 B, D$ ). In all of these rats, the anti-MBP T cells induced experimental autoimmune encephalomyelitis (EAE) (Lassmann et al., 1988; Mor and Cohen, 1992; O'Garra et al., 1997), a mild paralytic syndrome that developed by day 4 , reached a peak on day 7 , and resolved spontaneously by day 11.

The results of contusion and treatment in some of the rats were analyzed morphologically, 3 months after treatment, by retrograde labeling of the red nuclei and subsequent counting of the labeled rubrospinal neurons (see Materials and Methods). The total number of labeled red nuclei in the anti-MBP $\mathrm{T}$ cell-treated rats was
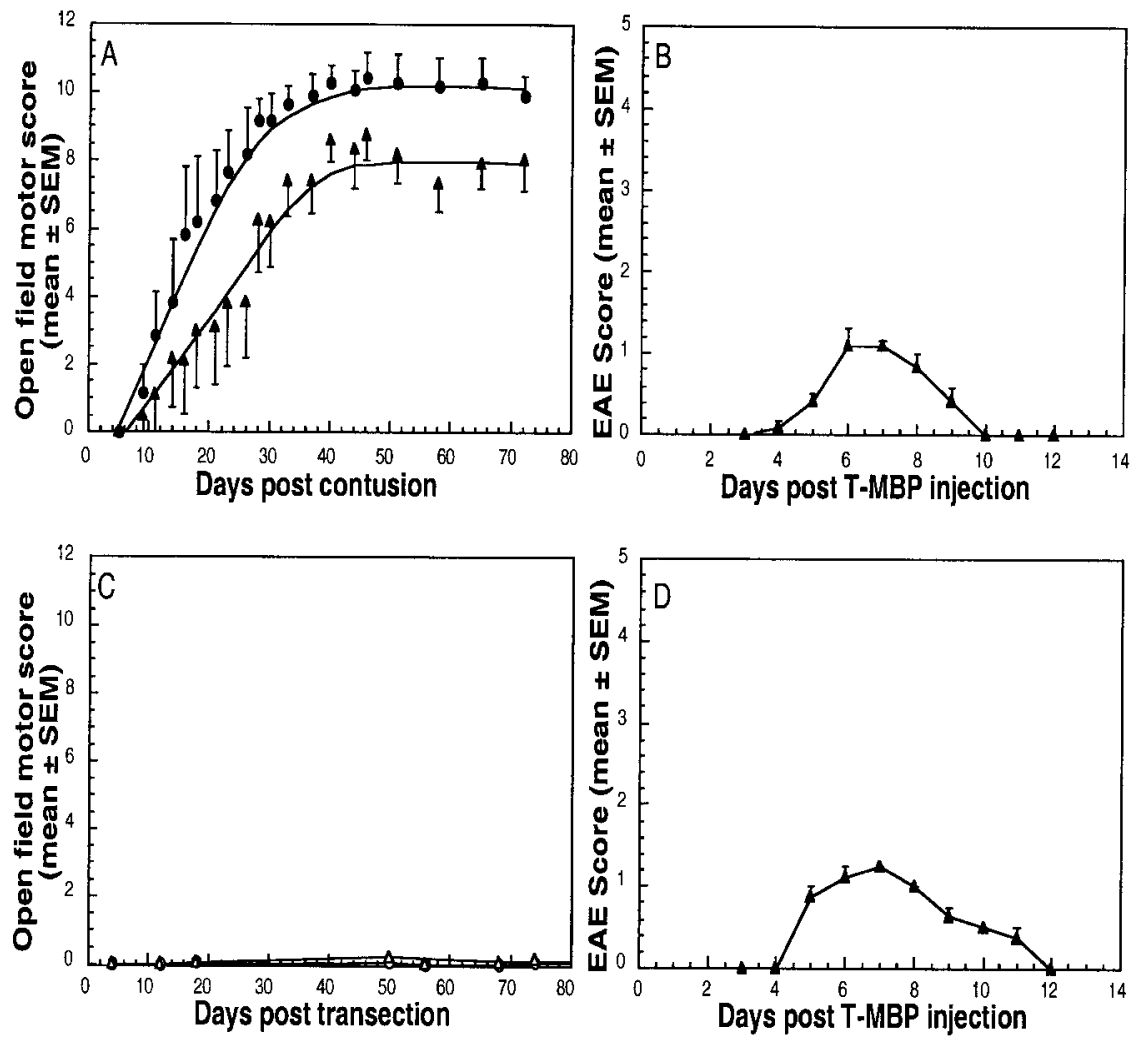

Figure 2. Anti-MBP T cells enhance recovery of voluntary motor activity after spinal cord contusion. $A$, Twelve rats were deeply anesthetized, laminectomized, and subjected to spinal cord contusion (T9). Six of the rats were then inoculated intraperitoneally with $10^{7}$ anti-MBP T cells in PBS (black circles), and the rest were injected with PBS (black squares). At the indicated times, locomotor behavior in an open field was scored. The results are expressed as the mean values for each group (error bars indicate SEM). The differences, tested by repeated ANOVA, were significant $(p<$ $0.05)$. $C$, In another group of rats, the spinal cords were completely transected and the rats were divided into subgroups receiving either $10^{7}$ anti-MBP $\mathrm{T}$ cells or PBS. No significant differences in locomotor behavior were seen between the two subgroups at any time during follow-up. $B, D$, Course of EAE development in sham-operated rats treated with anti-MBP $T$ cells. Lewis rats were subjected to sham operation (laminectomy but not contusion) and immediately injected with anti-MBP T cells. EAE was evaluated according to a neurological paralysis scale. Values represent means \pm SEM. 

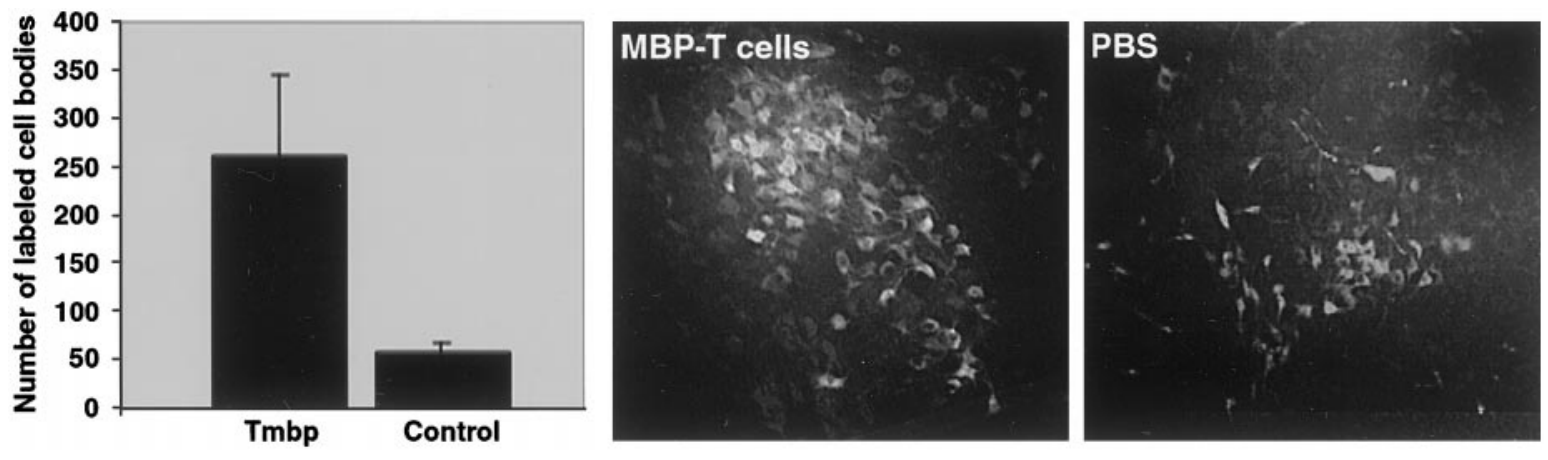

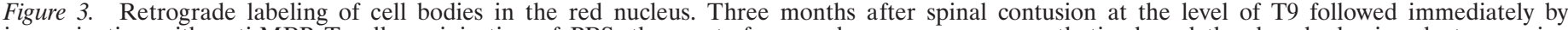

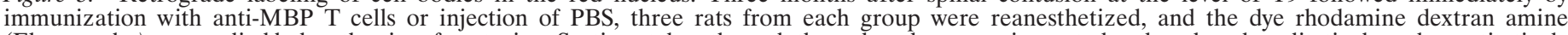

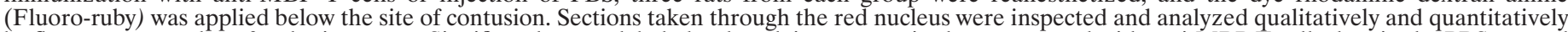

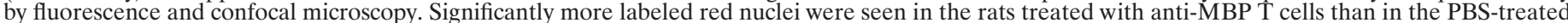

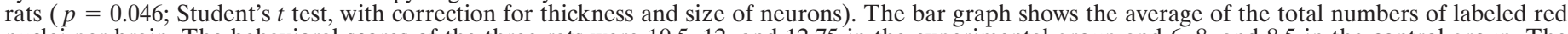

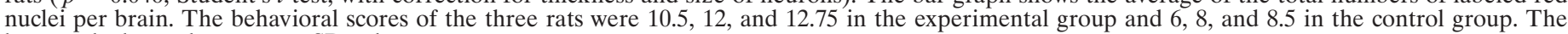
bar graph shows the mean $\pm \mathrm{SD}$ values.

fivefold higher than in the PBS-treated rats $(p=0.046$; Student's $t$ test). Representative photomicrographs of red nuclei taken from an anti-MBP $\mathrm{T}$ cell-treated rat and from a PBS-treated rat are shown in Figure 3. These findings indicate that the observed functional recovery is correlated with the morphological integrity of some descending tracts.

\section{Delayed administration of autoimmune $\mathrm{T}$ cells promotes recovery from spinal cord injury}

The results described above suggested that the therapeutic effect of the $\mathrm{T}$ cells is not restricted to contusive injuries of a particular severity, as long as the spinal cord is not completely cut. T cells were effective in rats with contusion at T7 (Hauben et al., 2000) and at T9 (present study) (Fig. $2 A$ ). To determine the therapeutic time window, we compared the outcome of $\mathrm{T} 7$ contusion injury in rats treated with anti-MBP T cells immediately after the contusion with that in rats treated 1 week later and in rats injected with PBS without $\mathrm{T}$ cells. The mean maximal locomotor score of the rats treated with anti-MBP T cells 1 week after contusion (BBB score of $7 \pm 1$ ) was significantly higher than that of the PBS-treated controls ( $2 \pm 0.8 ; p<0.01$ based on two-factor repeated ANOVA). Rats that had received immediate treatment with a single injection of anti-MBP $\mathrm{T}$ cells obtained an average BBB score of $7.7 \pm 1.4$ compared with $1.9 \pm 0.8$ in the PBS-treated group. Interestingly, however, although recovery onset was delayed in the rats immunized 1 week after injury relative to the immediately treated rats, the extent of recovery after the delayed treatment did not differ significantly from that observed after immediate treatment (Fig. 4). Maximal recovery was similar in both cases, suggesting that the degeneration of fibers that escape contusion does not become irreversible until at least 1 week after the injury; alternatively or in addition, the treatment with anti-MBP T cells might lead to some axonal sprouting (Beattie et al., 1997). The delay in recovery of motor activity might be merely a reflection of the transient paralysis (Fig. 4B) imposed by the injected cells, which had the simultaneous effect of neuroprotection and EAE induction. Thus, the EAE may have masked the ability to detect the neuroprotective effect until the rat had recovered from the disease.

\section{Active immunization with MBP promotes recovery from spinal cord injury}

The results described above suggested that systemic administration of anti-MBP T cells is effective even if delayed for at least 1 week after contusion. Active immunization with MBP emulsified in either IFA or complete Freund's adjuvant (CFA) is known to lead to a $\mathrm{T}$ cell-mediated autoimmune response within 1 week. Unlike immunization with CFA, which is accompanied by direct induction of EAE (Ben Nun and Cohen, 1982a,b), immunization with MBP in IFA does not lead to EAE in the immunized rat but does induce a cellular response to MBP that may lead to EAE induction after passive transfer of $\mathrm{T}$ cells from the immunized rat to naïve rats (Namikawa et al., 1982; Novikova et al., 2000). Because the conferment of neuroprotection by autoimmune $\mathrm{T}$ cells does not necessarily require that the $\mathrm{T}$ cells be encephalitogenic (Moalem et al., 1999), IFA was the adjuvant of choice for the present experiments on immunization.

Naïve rats were immunized with MBP emulsified in IFA. This was done 1 week before contusion injury, on the assumption that by the time of the injury, when the protective T cells would be needed, there would already be an adequate number of systemic anti-MBP T cells, without the risk of excessive encephalitogenicity that would mask or interfere with the neuroprotective effect, as shown in Figure 2, $B$ and $D$. Accordingly, 1 week before contusive injury at T7, six rats were immunized with MBP in IFA and six were injected with PBS in IFA. Three uninjured rats, immunized with MBP in IFA, showed no signs of EAE. Starting from 3 weeks after the injury, significantly better recovery was observed in the MBPimmunized rats (mean BBB score of $6.1 \pm 0.8$ compared with $3 \pm$ 0.8 in the PBS-injected rats; $p<0.05$ ) (Fig. 5). Active immunization is known to evoke both a cellular and a humoral response. Our experiments with the passive transfer of $\mathrm{T}$ cells suggest that this beneficial effect of the active immunization is $\mathrm{T}$ cell-mediated.

Some of the rats that showed recovery after active immunization (Fig. 5) were further analyzed by retrograde labeling of their red nuclei (see Materials and Methods). In the recovered MBP/IFAimmunized rats (with BBB scores of 9 or 7), the total number of labeled cells was fourfold higher than in the PBS/IFA-immunized controls (with BBB scores of 3 and 1.5) (Fig. 6A). In each examined rat from all of the experiments described above, the number of labeled rubrospinal neurons was found to be correlated with its BBB locomotor score (Fig. 6B).

\section{Spinal cord preservation by passive immunization confirmed by diffusion-anisotropy magnetic resonance imaging}

Three months after contusion injury at T9, images of axial slices taken from the spinal cords of anti-MBP T cell-treated rats showed areas of diffusion anisotropy along the entire length of the cord, and all cords manifested a continuous longitudinal structure (Fig. 7). In contrast, slices taken from the PBS-treated controls showed a loss of organized structure at the center of the lesion site, and the area of diffusion anisotropy in most of the analyzed slices was relatively small (Fig. 7). The behavioral outcome correlated well with the magnetic resonance imaging results: the higher the behavioral score, the larger the area of diff usion anisotropy found at the site of the lesion. Even small differences in the locomotor score (for example, 10 in experimental rats and eight in controls) (Fig. 7) were accompanied by noticeable differences in diffusion anisotropy. 

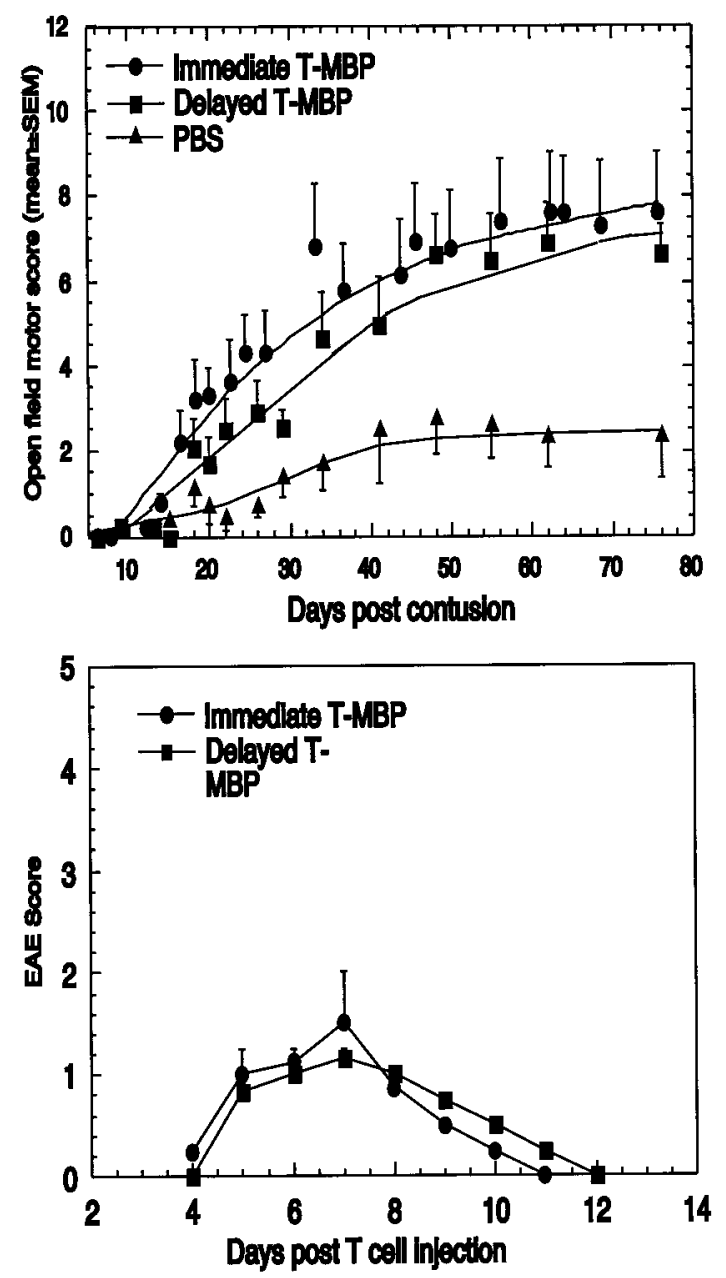

Figure 4. Spinal cord recovery after delayed administration of anti-MBP T cells. One week after contusion at the level of T7, rats $(n=15)$ were randomly divided into two groups for injection with either PBS $(n=8)$ or $10^{7}$ anti-MBP T cells $(n=7)$. $A$, The graph shows the mean \pm SEM locomotor activity scores at the indicated periods after T7 contusion. Plateau values reached by the anti-MBP $\mathrm{T}$ cell-treated rats were significantly higher than those reached by the controls $(p<0.001$; ANOVA). For comparison, a similar experiment using five PBS-treated rats and six rats treated immediately with anti-MBP T cells is also shown here. There was no difference between the immediate and the delayed $\mathrm{T}$ cell treatment in terms of the maximal plateau values. Another group of rats with contusion at T7 received anti-OVA T cells. No effect was observed relative to PBStreated rats. $B$, The course of EAE development in sham-operated rats treated with anti-MBP T cells. Lewis rats were subjected to sham operation (laminectomy but not contusion) and immediately injected with anti-MBP $T$ cells. EAE was evaluated according to a neurological paralysis scale. Values represent means \pm SEM.

\section{Immunohistochemical evidence for spinal cord preservation}

To further substantiate our suggestion that the observed recovery of the autoimmune $\mathrm{T}$ cell-treated spinal cords was attributable to tissue preservation, 5 months after injury and treatment we examined three cords from the anti-MBP T cell-treated group and three from the PBS-treated control group (all taken from the set of T7-contused rats) by phase microscopy, as well as by immunohistochemistry using antibodies directed against NFs and GFAP. Confocal microscopy of the PBS-treated spinal cords showed an enlarged site of injury, loss of neural tissue, and large cyst-like structures. In contrast, the neural tissue taken from the anti-MBP $\mathrm{T}$ cell-treated group, although partly damaged, showed a high degree of preservation, and if any cysts were present, they were very small (Fig. 8). Staining for GFAP, used to delineate the site of the injury (Blaugrund et al., 1992), showed a wide gap at the lesion site in control cords (Fig. 9A), whereas in the cords from the

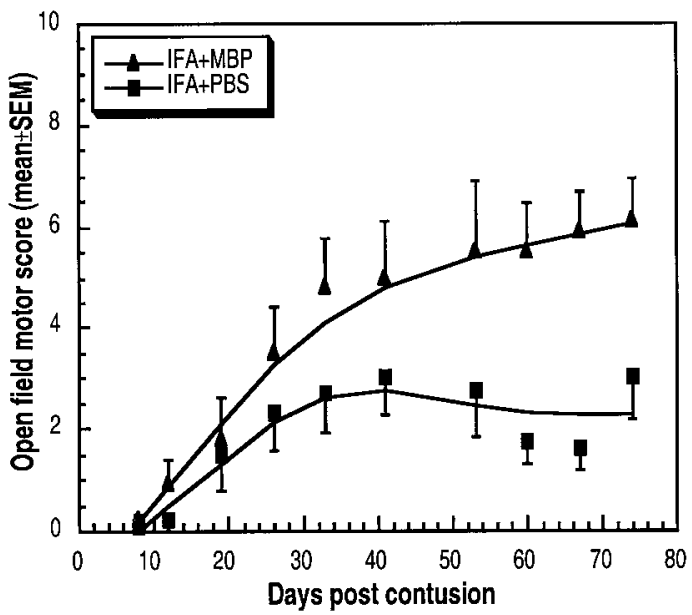

Figure 5. Promotion of spinal cord recovery by active immunization with MBP. Six rats were immunized subcutaneously with MBP in IFA, and six were injected with PBS in IFA. One week later, the rats were deeply anesthetized, laminectomized, and subjected to spinal cord contusion at T7. At the indicated times, locomotor behavior in an open field was scored. The results are expressed as the mean values for each group (error bars indicate SEM). The differences, tested by repeated ANOVA, were significant $(p<0.05)$.

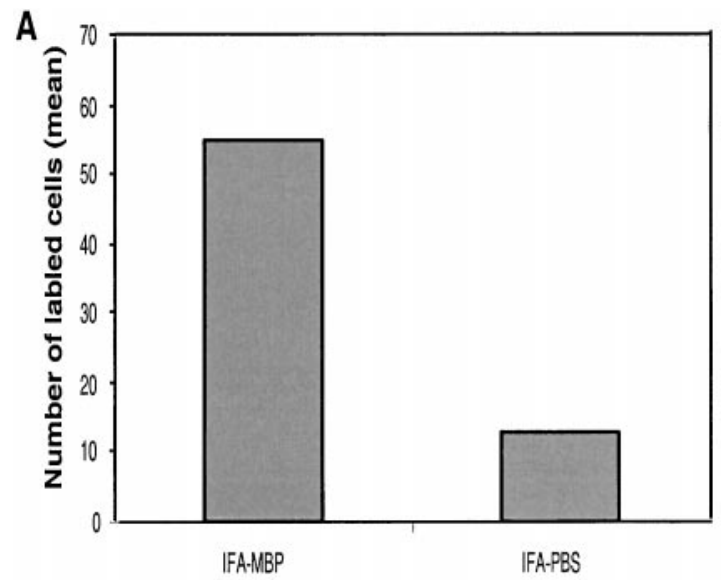

B

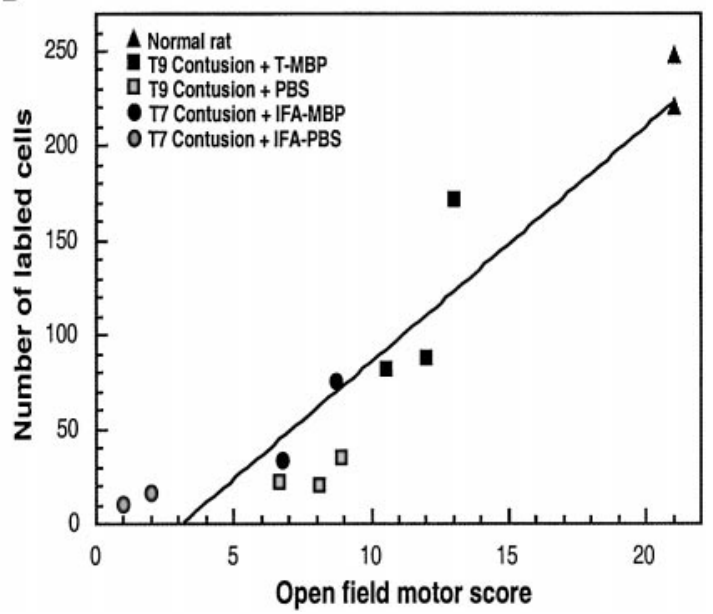

Figure 6. Correlation between BBB locomotor score and the number of retrogradely labeled red nuclei. Rats were actively immunized with MBP, and this was followed 1 week later by contusion. Two months after injury, a dye was applied below the primary contusion site. Five days later, the rats were killed, and their brains were excised and analyzed. $A$, Bar graphs show the number of labeled rubrospinal neurons in contused rats immunized with MBP in IFA or injected with PBS in IFA. $B$, Correlation between BBB locomotor score and the number of retrogradely labeled rubrospinal neurons. The graph shows the number of labeled neurons and the BBB score for each rat. The data for all of the examined rats are included. 


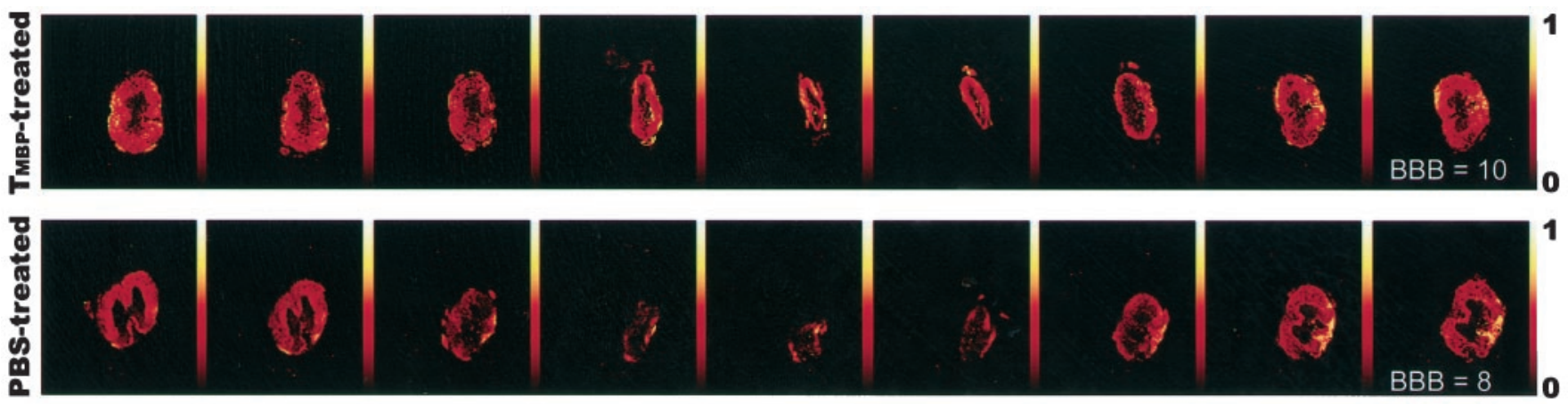

Figure 7. Maps showing diff usion anisotropy of the contused spinal cords. Rats were deeply anesthetized, and their excised spinal cords were immediately fixed and placed in $5 \mathrm{~mm}$ nuclear magnetic resonance tubes. The figure shows representative maps of spinal cords of anti-MBP T cell-treated rats and control rats, after contusion at T8-T9. Colors correspond to anisotropy ratios. The maps show the preservation of longitudinally ordered tissue at the lesion sites of the anti-MBP T cell-treated rats. Note that, in the controls, the site of injury is much larger than in rats from the anti-MBP T cell-treated group.
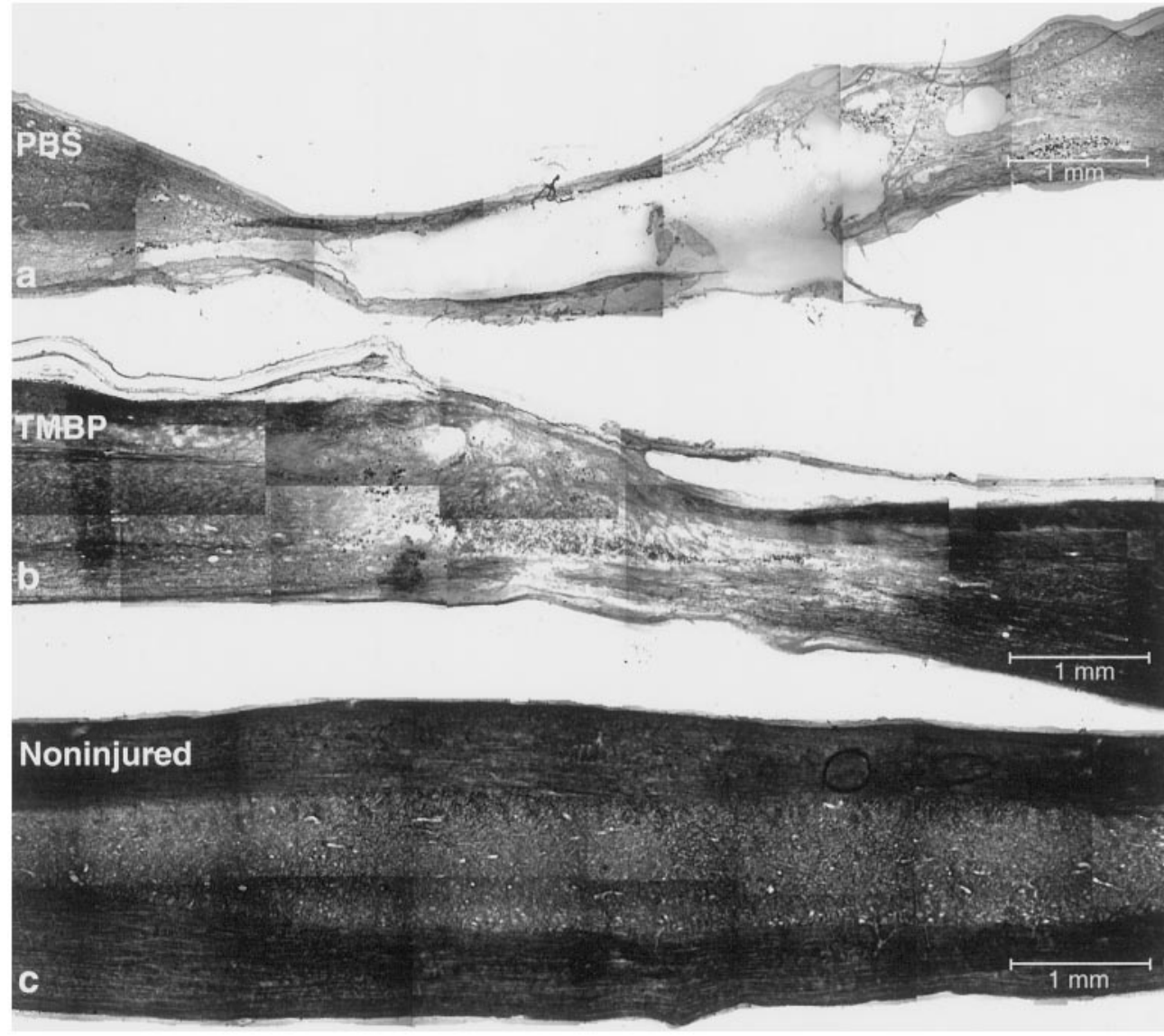

Figure 8. Phase microscopy and histochemical staining of contused spinal cords. Rats were subjected to spinal cord contusion (T7) and were treated immediately with anti-MBP T cells or with PBS. After 5 months, the spinal cords from three PBS-treated controls and three antiMBP T cell-treated rats were excised and processed for confocal microscopy. Representative micrographs from each group are shown. Note the large gap and the cysts in the neural tissues of a PBS-treated rat (a) compared with an anti-MBP $\mathrm{T}$ cell-treated rat $(b)$. For comparison, a phase micrograph of a sham-operated spinal cord is included $(c)$.
anti-MBP T cell-treated group, the gap was only approximately the size of the dropped weight and was narrower than the full width of the nerve (Fig. 9B). In correlation with the above findings, staining for NFs in the PBS-treated control cords showed continuity of only a few nerve fibers and a large gap between disrupted fibers at the site of the lesion. (Fig. 9C). In the anti-MBP T cell-treated cords, however, there was a sizable number of well organized nerve fibers across the lesion site, pointing to the rescue of viable tissue rather than the formation of newly growing and newly organized neural tissue (Fig. 9D). These findings appear to confirm that treatment with the anti-MBP $\mathrm{T}$ cells promoted rescue and protection of partially damaged spinal cord, thereby reducing the lateral and longitudinal spread of damage. Cross-sections taken from the center of the site of injury in recovered anti-MBP T cell-treated rats and stained with luxol or with hematoxylin and eosin (H\&E) showed well organized neural tissue containing myelinated axons (Fig. 10B,D,F,I). Corresponding sections from contused spinal cords of PBS-treated controls showed a profusion of cells and a lack of organized tissue (Fig. 10 $A, C, E, G$ ). Interestingly, neuronal cell bodies can be seen in the sections from anti-MBP T cell-treated rats but hardly at all in the sections from PBS-treated controls.

\section{DISCUSSION}

In the last few years, it has become apparent that, although damage to the spinal cord may be partial, the functional loss is often far worse than can be accounted for by the severity of the initial insult. Both the insult and the self-propagating process of secondary degeneration play a decisive part in determining the final outcome of the injury. A substantial research effort has been directed to arresting secondary degeneration. In the present study, we describe a cell-mediated immune therapy that, by enhancing what appears to be a natural mechanism of self-protection (Schwartz et al., 1999), leads (after only one treatment) to long-lasting recovery. Notable features of the neuroprotection mediated by autoimmune $\mathrm{T}$ cells in 

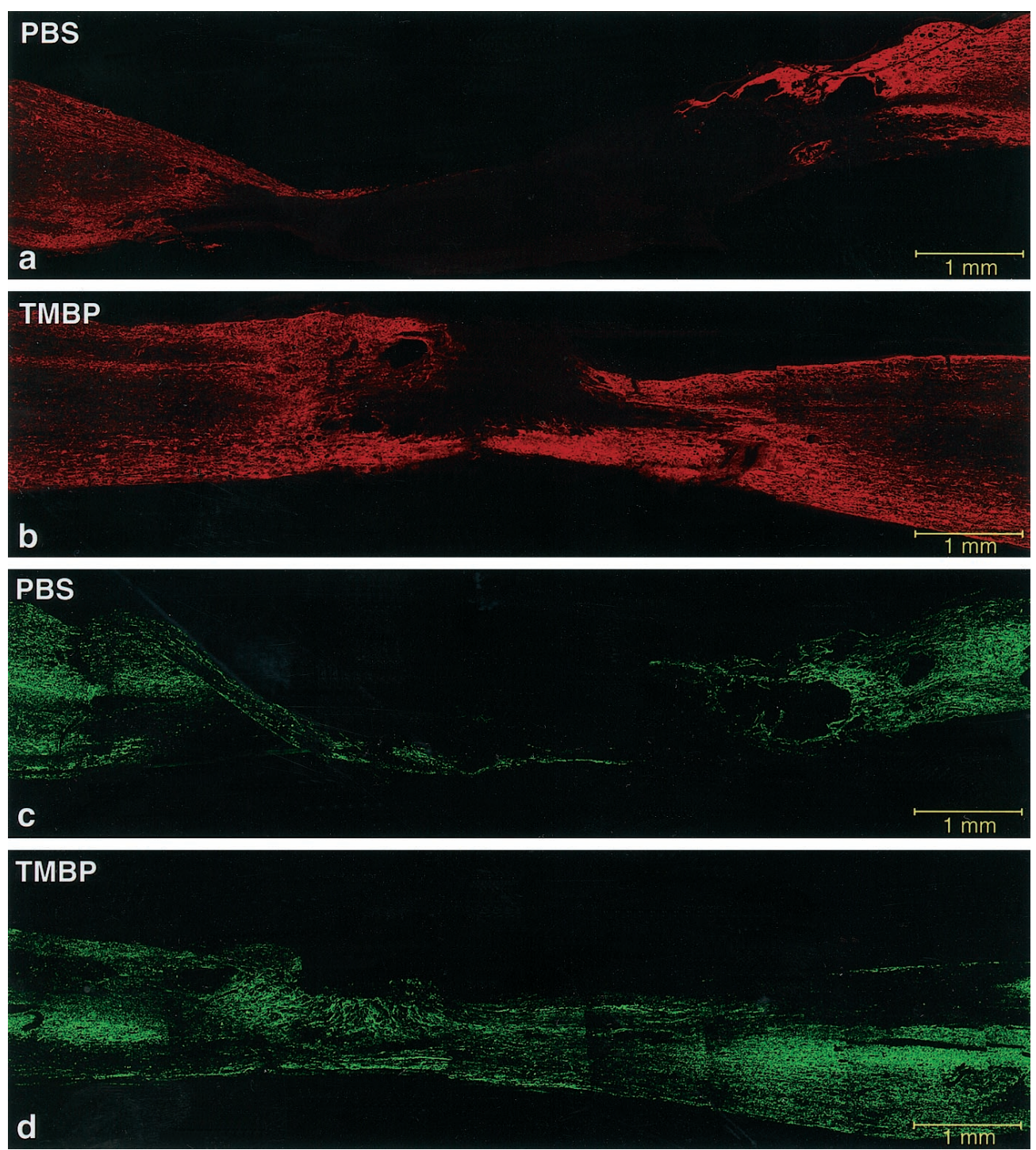

Figure 9. Fluorescence micrographs of spinal cords stained for GFAP and NFs. Sections taken from the preparation described in Figure 8 were analyzed by immunohistochemical staining for GFAP to delineate the site of injury. Note the gap in staining of the PBS-treated cord $(a)$ compared with the anti-MBP $\mathrm{T}$ celltreated cord $(b)$. Sections were also analyzed for NFs. The gap between the severed ends of axons is smaller in the rat treated with anti-MBP T cells $(d)$ than in the PBS-treated rat $(c)$. this study were its effectiveness even when the T cells were administered as late as 1 week after the injury, and the fact that it could be achieved by active immunization.

$\mathrm{T}$ cells have been shown to be the source of a variety of neurotrophic factors and cytokines (Ehrhard et al., 1993; Heese et al., 1998; Besser and Wank, 1999; Kerschensteiner et al., 1999), some or all of which may be supportive and protective after CNS injury (Bethea et al., 1998; Artis et al., 1999; Loddick and Rothwell, 1999). We have shown that the secretion of neurotrophic factors by $\mathrm{T}$ cells, like the secretion of cytokines, is dependent on reactivation of the $\mathrm{T}$ cells by their antigen and professional antigen-presenting cells. It is therefore conceivable that the neuroprotective effect of the autoimmune $\mathrm{T}$ cells is mediated by the local secretion of certain factors once the $\mathrm{T}$ cells encounter their specific antigens, the myelin proteins, at the lesion site and are reactivated by them (Moalem, Gdalyahu, Shani, Otten, Lazarovici, Cohen, and Schwartz, unpublished observations). We have shown previously that the T cellmediated neuroprotection involves factors that trigger intracellular signal transduction pathway(s) involving tyrosine kinase. Thus, local application of the protein kinase inhibitor K252a, a selective inhibitor of signal transduction pathways associated with tyrosine kinase (Koizumi et al., 1988), weakens the neuroprotective activity of the $\mathrm{T}$ cells without affecting the transient induction of EAE (Moalem, Gdalyahu, Shani, Otten, Lazarovici, Cohen, and Schwartz, unpublished observations). Other studies have pointed to a neuroprotective effect of neurotrophic and other growth factors in spinal cord injuries (Bregman et al., 1997; Davies et al.,
1997; Blesch et al., 1998; Houle et al., 1998; Houweling et al., 1998; Franzen et al., 1999; Houle and Ye, 1999). It seems reasonable to suggest that, because of its heterogeneous neuronal subtypes and the complexity of the degenerative process, the injured spinal cord may respond positively to a variety of factors. Therefore, suitably activated $\mathrm{T}$ cells might have an advantage over any individual therapeutic agent by supplying a number of remedial factors, whose production and local secretion are regulated by signals derived locally from the damaged tissue, presumably in accordance with tissue requirements.

Several studies have shown that inflammation at an early stage after spinal cord injury may have both deleterious and beneficial effects on the injured nerves, depending (at least in part) on the repertoire of locally produced cytokines. Thus, for example, the anti-inflammatory cytokine interleukin-10 can be beneficial soon after injury and harmful later on (Bethea et al., 1998). It is conceivable that the $\mathrm{T}$ cells homing to the lesion site might undergo a change in phenotype in accordance with the nature of the extracellular environment of the lesion and the consequent requirements of the tissue. Microglia and macrophages were shown to be effective in promoting axonal regrowth under certain conditions (Prewitt et al., 1997; Franzen et al., 1998; Rapalino et al., 1998), yet there is evidence suggesting that depletion of macrophages may be beneficial for the damaged spinal cord (Popovich et al., 1999). It therefore seems that whether macrophages exhibit a beneficial or a detrimental effect will depend on their number, state 

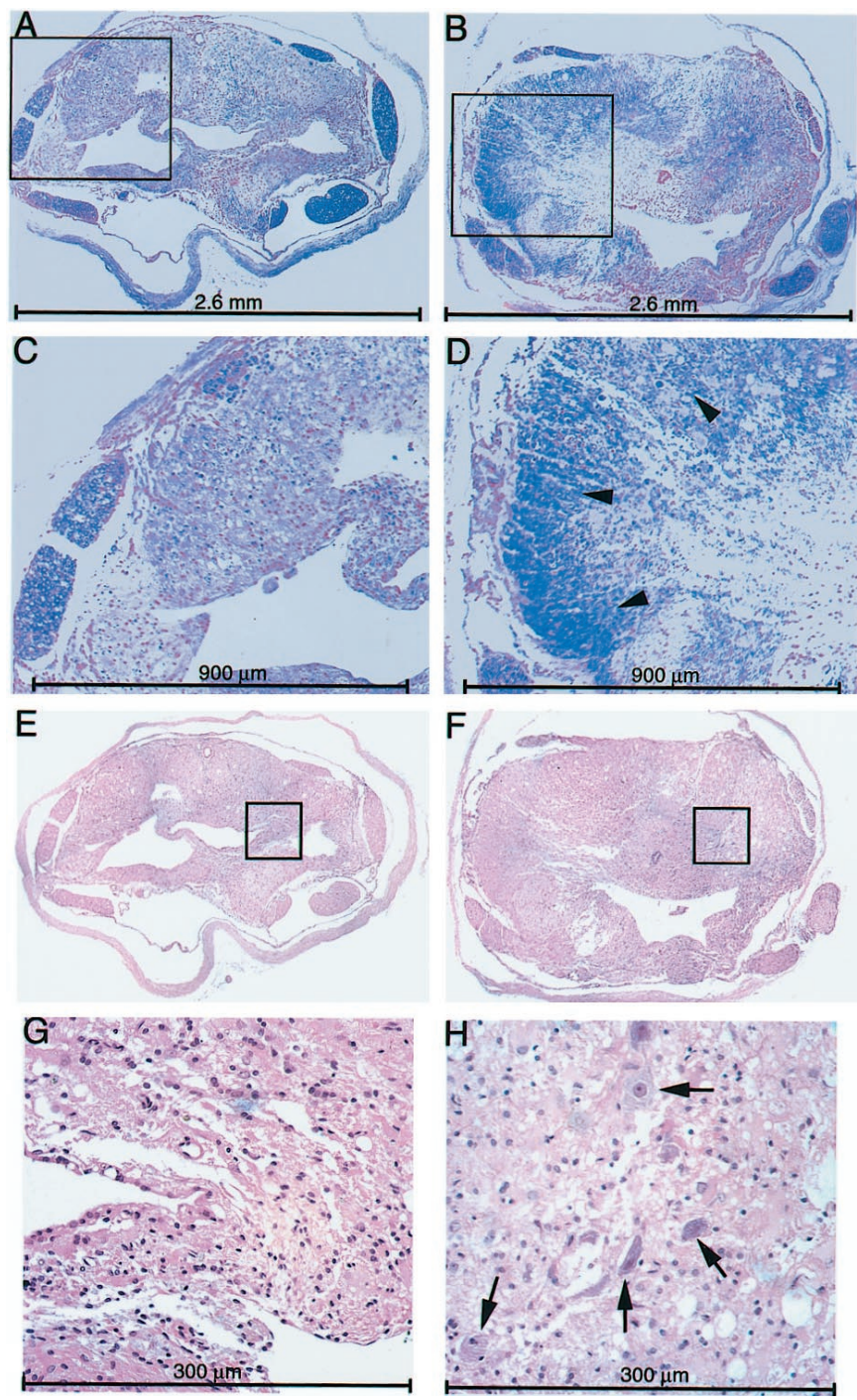

Figure 10. Light microscopy of cross-sections from the site of injury. Transverse sections $(4 \mu \mathrm{m})$ were taken from the center of the lesion site of contused spinal cords treated with anti-MBP T cells or PBS and stained with $\mathrm{H} \& \mathrm{E}(E-H)$ or luxol $(A-D) . A, C, E$, and $G$ show sections from control rats. $B, D, F$, and $H$ show sections from rats treated with anti-MBP T cells. Arrowheads and arrows point to myelinated axons and neuronal cell bodies, respectively. $C$ and $D$ are enlargements of the boxed areas seen in $A$ and $B$; $G$ and $H$ are enlargements of $E$ and $F$.

of activation, and cellular context, and whether the tissue requires rescue or regrowth (Hirschberg and Schwartz, 1995).

The morphological and functional recovery observed in the present study appears to be attributable to the rescue of neurons that escaped the direct effects of the contusive injury. This interpretation is based on the following: (1) the brevity of the time lag between injury and recovery, too short for any measurable regeneration to have occurred (Rapalino et al., 1998); (2) the lack of any effect of the treatment on completely transected cords (in which there are no neurons to be rescued); and (3) the results of morphological and imaging analyses, showing structures resembling normal tissue rather than newly regrowing, reorganized tissue. In a previous study, we showed that the regrowth of severely injured CNS axons is promoted by macrophages, representing the innate arm of the immune response (Lazarov Spiegler et al., 1996; Rabchevsky and Streit, 1997; Rapalino et al., 1998; Streit et al., 1998). It is worth investigating whether the autoimmune $\mathrm{T}$ cells, in addition to preserving viable neuronal tissue, can directly or indirectly promote axonal sprouting and regrowth. It is known that active immunization awakens other immune responses in addition to those involving $\mathrm{T}$ cells. We therefore cannot rule out the possible occurrence of antibody and macrophage involvement in the lesion site after active immunization with MBP, unlike after passive immunization with the T cells. The effectiveness of immunization with MBP 1 week before injury argues in favor of a T cell-mediated effect, because a time window of 1 week after a single immunization with IFA is probably not long enough for a significant humoral response to develop. That the effect is mediated by $\mathrm{T}$ cells is further supported by the finding that no effect is induced by passive transfer of serum collected from immunized rats (data not shown). It is possible, however, that these other immune-associated activities evoked by the active immunization contribute further to the beneficial effect of the T cells. Possible contributory factors might include macrophages (Rapalino et al., 1998) and antibodies (Huang et al., 1999) or other forms of immune intervention (Dyer et al., 1998), none of which leads to tissue preservation.

In most tissues, injury-induced damage triggers a cellular immune response that acts to repair the tissue and preserve its homeostasis. This response has been attributed to macrophages and other cells comprising the innate arm of the immune system. Adaptive immunity, on the other hand, is the responsibility of lymphocytes and, according to traditional teaching, represents the system of defense of the body against foreign dangers (Burnet, 1971). Our studies now show, however, that the adaptive T cell immune response can be protective, even when there is no invasion by foreign pathogens. In this case, the $\mathrm{T}$ cells, rather than being directed against invaders, are specifically directed against tissue self antigens (Schwartz et al., 1999). In other words, it seems that autoimmunity can be physiological (Cohen, 1992, 1999). The finding that the autoimmune response can be advantageous suggests that natural autoimmune $\mathrm{T}$ cells may have undergone positive selection during ontogeny, as proposed by the theory of the immunological homunculus (Cohen, 1992), and are not merely a default resulting from the escape from negative selection of $\mathrm{T}$ cells that recognize self antigens (Cohen, 1992; Janeway, 1992). It was reported recently that injury to the spinal cord triggers an autoimmune response to MBP (Popovich et al., 1996; Kil et al., 1999), but it was not clear whether this response was detrimental or beneficial (Schnell et al., 1997; Popovich et al., 1998). Our recent unpublished data pointing to a beneficial effect of the endogenous autoimmune anti-MBP $\mathrm{T}$ cell response are in line with the present data in suggesting that activation of anti-MBP $\mathrm{T}$ cells can indeed be beneficial. However, a supplement of exogenous autoimmune $\mathrm{T}$ cells may be needed to overcome the restrictions on immune reactivity imposed as a result of the immune-privileged character of the CNS (Lotan and Schwartz, 1994; Schwartz et al., 1999). A careful and accurate interpretation of the involvement of the immune system in recovery after spinal cord injury, taking into account the type of immunization (passive or active), choice of adjuvant, and timing, can be expected to lead to more effective exploitation of immune cells in the interests of treatment and possibly a cure.

\section{REFERENCES}

Artis D, Humphreys NE, Bancroft AJ, Rothwell NJ, Potten CS, Grencis RK (1999) Tumor necrosis factor alpha is a critical component of interleukin 13-mediated protective T helper cell type 2 responses during helminth infection. J Exp Med 190:953-962.

Basso DM, Beattie MS, Bresnahan JC (1995) A sensitive and reliable locomotor rating scale for open field testing in rats. J Neurotrauma 12:1-21.

Basso DM, Beattie MS, Bresnahan JC (1996) Graded histological and locomotor outcomes after spinal cord contusion using the NYU weightdrop device versus transection. Exp Neurol 139:244-256.

Bavetta S, Hamlyn PJ, Burnstock G, Lieberman AR, Anderson PN (1999) The effects of F K506 on dorsal column axons following spinal cord injury in adult rats: neuroprotection and local regeneration. Exp Neurol 158:382-393.

Beattie MS, Bresnahan JC, Komon J, Tovar CA, Van Meter M, Anderson DK, Faden AI, Hsu CY, Noble LJ, Salzman S, Young W (1997) Endogenous repair after spinal cord contusion injuries in the rat. Exp Neurol 148:453-463.

Behrmann DL, Bresnahan JC, Beattie MS (1994) Modeling of acute spinal 
cord injury in the rat: neuroprotection and enhanced recovery with methylprednisolone, U-74006F and YM-14673. Exp Neurol 126:61-75.

Ben Nun A, Cohen IR (1982a) Experimental autoimmune encephalomyelitis (EAE) mediated by T cell lines: process of selection of lines and characterization of the cells. J Immunol 129:303-308.

Ben Nun A, Cohen IR (1982b) Spontaneous remission and acquired resistance to autoimmune encephalomyelitis (EAE) are associated with suppression of T cell reactivity: suppressed EAE effector T cells recovered as T cell lines. J Immunol 128:1450-1457.

Ben Nun A, Wekerle H, Cohen IR (1981) The rapid isolation of clonable antigen-specific $\mathrm{T}$ lymphocyte lines capable of mediating autoimmune encephalomyelitis. Eur J Immunol 11:195-199.

Besser M, Wank R (1999) Cutting edge: clonally restricted production of the neurotrophins brain-derived neurotrophic factor and neurotrophin-3 mRNA by human immune cells and Th1/Th2-polarized expression of their receptors. J Immunol 162:6303-6306.

Bethea JR, Castro M, Keane RW, Lee TT, Dietrich WD, Yezierski RP (1998) Traumatic spinal cord injury induces nuclear factor-kappaB activation. J Neurosci 18:3251-3260.

Blaugrund E, Duvdevani R, Lavie V, Solomon A, Schwartz M (1992) Disappearance of astrocytes and invasion of macrophages following crush injury of adult rodent optic nerves: implications for regeneration. Exp Neurol 118:105-115.

Blesch A, Tuszynski MH (1997) Robust growth of chronically injured spinal cord axons induced by grafts of genetically modified NGFsecreting cells. Exp Neurol 148:444-452.

Blesch A, Grill RJ, Tuszynski MH (1998) Neurotrophin gene therapy in CNS models of trauma and degeneration. Prog Brain Res 117:473-484.

Blight AR (1989) Effect of 4-aminopyridine on axonal conduction-block in chronic spinal cord injury. Brain Res Bull 22:47-52.

Brandt HM, Apkarian AV (1992) Biotin-dextran: a sensitive anterograde tracer for neuroanatomic studies in rat and monkey. J Neurosci Methods 45:35-40.

Bregman BS, McAtee M, Dai HN, Kuhn PL (1997) Neurotrophic factors increase axonal growth after spinal cord injury and transplantation in the adult rat. Exp Neurol 148:475-494.

Bregman BS, Broude E, McAtee M, Kelley MS (1998) Transplants and neurotrophic factors prevent atrophy of mature CNS neurons after spinal cord injury. Exp Neurol 149:13-27.

Burnet FM (1971) "Self-recognition" in colonial marine forms and flowering plants in relation to the evolution of immunity. Nature 232:230-235.

Caroni P, Schwab ME (1988) Antibody against myelin-associated inhibitor of neurite growth neutralizes nonpermissive substrate properties of CNS white matter. Neuron 1:85-96.

Cheng H, Cao Y, Olson L (1996) Spinal cord repair in adult paraplegic rats: partial restoration of hind limb function. Science 273:510-513.

Chong MS, Woolf CJ, Haque NS, Anderson PN (1999) Axonal regeneration from injured dorsal roots into the spinal cord of adult rats. J Comp Neurol 410:42-54.

Cohen IR (1992) The cognitive paradigm and the immunological homunculus. Immunol Today 13:490-494.

Cohen IR (1999) Tending Adam's garden. Evolving the cognitive immune self. London: Academic.

Constantini S, Young W (1994) The effects of methylprednisolone and the ganglioside GM1 on acute spinal cord injury in rats. J Neurosurg 80:97-111

Crowe MJ, Bresnahan JC, Shuman SL, Masters JN, Beattie MS (1997) Apoptosis and delayed degeneration after spinal cord injury in rats and monkeys. Nat Med [Erratum (1997) 3:240] 3:73-76.

Davies SJ, Fitch MT, Memberg SP, Hall AK, Raisman G, Silver J (1997) Regeneration of adult axons in white matter tracts of the central nervous system. Nature 390:680-683.

Dyer JK, Bourque JA, Steeves JD (1998) Regeneration of brainstemspinal axons after lesion and immunological disruption of myelin in adult rat. Exp Neurol 154:12-22.

Ehrhard PB, Erb P, Graumann U, Otten U (1993) Expression of nerve growth factor and nerve growth factor receptor tyrosine kinase Trk in activated CD4-positive T-cell clones. Proc Natl Acad Sci USA 90:10984-10988.

Faden AI (1993) Experimental neurobiology of central nervous system trauma. Crit Rev Neurobiol 7:175-186.

Franzen R, Schoenen J, Leprince P, Joosten E, Moonen G, Martin D (1998) Effects of macrophage transplantation in the injured adult rat spinal cord: a combined immunocytochemical and biochemical study. J Neurosci Res 51:316-327.

Franzen R, Martin D, Daloze A, Moonen G, Schoenen J (1999) Grafts of meningeal fibroblasts in adult rat spinal cord lesion promote axonal regrowth. NeuroReport 10:1551-1556.

Gruner JA, Yee AK, Blight AR (1996) Histological and functional evaluation of experimental spinal cord injury: evidence of a stepwise response to graded compression. Brain Res 729:90-101.

Hauben E, Nevo U, Yoles E, Moalem G, Agranov E, Mor F, Akselrod S, Neeman M, Cohen IR, Schwartz M (2000) Autoimmune T cells as potential neuroprotective therapy for spinal cord injury. Lancet 355:286-287.

Heese K, Fiebich BL, Bauer J, Otten U (1998) NF-kappaB modulates lipopolysaccharide-induced microglial nerve growth factor expression. Glia 22:401-407.

Hickey WF, Hsu BL, Kimura H (1991) T-lymphocyte entry into the central nervous system. J Neurosci Res 28:254-260.

Hirschberg DL, Schwartz M (1995) Macrophage recruitment to acutely injured central nervous system is inhibited by a resident factor: a basis for an immune-brain barrier. J Neuroimmunol 61:89-96.

Hirschberg DL, Moalem G, He J, Mor F, Cohen IR, Schwartz M (1998) Accumulation of passively transferred primed $\mathrm{T}$ cells independently of their antigen specificity following central nervous system trauma. J Neuroimmunol 89:88-96.

Houle JD, Ye JH (1999) Survival of chronically-injured neurons can be prolonged by treatment with neurotrophic factors. Neuroscience 94:929-936.

Houle JD, Schramm P, Herdegen T (1998) Trophic factor modulation of c-Jun expression in supraspinal neurons after chronic spinal cord injury. Exp Neurol 154:602-611.

Houweling DA, Bar PR, Gispen WH, Joosten EA (1998) Spinal cord injury: bridging the lesion and the role of neurotrophic factors in repair. Prog Brain Res 117:455-471.

Huang DW, McKerracher L, Braun PE, David S (1999) A therapeutic vaccine approach to stimulate axon regeneration in the adult mammalian spinal cord. Neuron 24:639-647.

Janeway Jr CA (1992) The immune system evolved to discriminate infectious nonself from noninfectious self. Immunol Today 13:11-16.

Kalb LY (1995) Recovery from spinal cord injury: new approaches. The Neuroscientist 1:321-327.

Kerschensteiner M, Gallmeier E, Behrens L, Leal VV, Misgeld T, Klinkert WE, Kolbeck R, Hoppe E, Oropeza-Wekerle RL, Bartke I, Stadelmann C, Lassmann H, Wekerle H, Hohlfeld R (1999) Activated human T cells, B cells, and monocytes produce brain-derived neurotrophic factor in vitro and in inflammatory brain lesions: a neuroprotective role of inflammation? J Exp Med 189:865-870.

Kil K, Zang YC, Yang D, Markowski J, Fuoco GS, Vendetti GC, Rivera VM, Zhang JZ (1999) $\mathrm{T}$ cell responses to myelin basic protein in patients with spinal cord injury and multiple sclerosis. J Neuroimmunol 98:201-207.

Koizumi S, Contreras ML, Matsuda Y, Hama T, Lazarovici P, Guroff G (1988) K-252a: a specific inhibitor of the action of nerve growth factor on PC 12 cells. J Neurosci 8:715-721.

Lassmann H, Brunner C, Bradl M, Linington C (1988) Experimental allergic encephalomyelitis: the balance between encephalitogenic T lymphocytes and demyelinating antibodies determines size and structure of demyelinated lesions. Acta Neuropathol (Berl) 75:566-576.

Lazarov Spiegler O, Solomon AS, Zeev Brann AB, Hirschberg DL, Lavie V, Schwartz M (1996) Transplantation of activated macrophages overcomes central nervous system regrowth failure. FASEB J 10:1296-1302.

Li Y, Field PM, Raisman G (1997) Repair of adult rat corticospinal tract by transplants of olfactory ensheathing cells. Science 277:2000-2002.

Loddick SA, Rothwell NJ (1999) Mechanisms of tumor necrosis factor alpha action on neurodegeneration: interaction with insulin-like growth factor-1. Proc Natl Acad Sci USA 96:9449-9451.

Lotan M, Schwartz M (1994) Cross talk between the immune system and the nervous system in response to injury: implications for regeneration. FASEB J 8:1026-1033.

Miya D, Giszter S, Mori F, Adipudi V, Tessler A, Murray M (1997) Fetal transplants alter the development of function after spinal cord transection in newborn rats. $\mathrm{J}$ Neurosci 17:4856-4872

Moalem G, Leibowitz-Amit R, Yoles E, Mor F, Cohen IR, Schwartz M (1999) Autoimmune T cells protect neurons from secondary degeneration after central nervous system axotomy. Nat Med 5:49-55.

Mor F, Cohen IR (1992) T cells in the lesion of experimental autoimmune encephalomyelitis. Enrichment for reactivities to myelin basic protein and to heat shock proteins. J Clin Invest 90:2447-2455.

Namikawa T, Richert JR, Driscoll BF, Kies MW, Alvord Jr EC (1982) Transfer of allergic encephalomyelitis with spleen cells from donors sensitized with myelin basic protein in incomplete Freund's adjuvant. J Immunol 128:932-934.

Neumann S, Woolf CJ (1999) Regeneration of dorsal column fibers into and beyond the lesion site following adult spinal cord injury. Neuron 23:83-91.

Nevo U, Hauben E, Yoles E, Agranov E, Akselrod S, Schwartz M, Neeman M (2000) Diffusion anisotropy MRI for quantitative assessment of recovery in injured rat spinal cord. Magn Reson Med, in press.

Novikova LN, Novikov LN, Kellerth JO (2000) Survival effects of BDNF and NT-3 on axotomized rubrospinal neurons depend on the temporal pattern of neurotrophin administration. Eur J Neurosci 12:776-780.

O'Garra A, Steinman L, Gijbels K (1997) CD4+ T-cell subsets in autoimmunity. Curr Opin Immunol 9:872-883.

Panter SS, Yum SW, Faden AI (1990) Alteration in extracellular amino acids after traumatic spinal cord injury. Ann Neurol 27:96-99.

Popovich PG, Stokes BT, Whitacre CC (1996) Concept of autoimmunity following spinal cord injury: possible roles for $\mathrm{T}$ lymphocytes in the traumatized central nervous system. J Neurosci Res 45:349-363.

Popovich PG, Whitacre CC, Stokes BT (1998) Is spinal cord injury an autoimmune disease? The Neuroscientist 4:71-76.

Popovich PG, Guan Z, Wei P, Huitinga I, van Rooijen N, Stokes BT (1999) 
Depletion of hematogenous macrophages promotes partial hindlimb recovery and neuroanatomical repair after experimental spinal cord injury. Exp Neurol 158:351-365.

Povlishock JT, Jenkins LW (1995) Are the pathobiological changes evoked by traumatic brain injury immediate and irreversible? Brain Pathol 5:415-426.

Prewitt CM, Niesman IR, Kane CJ, Houle JD (1997) Activated macrophage/microglial cells can promote the regeneration of sensory axons into the injured spinal cord. Exp Neurol 148:433-443.

Rabchevsky AG, Streit WJ (1997) Grafting of cultured microglial cells into the lesioned spinal cord of adult rats enhances neurite outgrowth J Neurosci Res 47:34-48.

Rabchevsky AG, Fugaccia I, Fletcher-Turner A, Blades DA, Mattson MP, Scheff SW (1999) Basic fibroblast growth factor (bFGF) enhances tissue sparing and functional recovery following moderate spinal cord injury. J Neurotrauma 16:817-830.

Rapalino O, Lazarov-Spiegler O, Agranov E, Velan GJ, Fraidakis M, Yoles E, Solomon A, Gepstein R, Katz A, Belkin M, Hadani M, Schwartz M (1998) Implantation of stimulated homologous macrophages results in partial recovery of paraplegic rats. Nat Med 4:814-821.

Reier PJ, Stokes BT, Thompson FJ, Anderson DK (1992) Fetal cell grafts into resection and contusion/compression injuries of the rat and cat spinal cord. Exp Neurol 115:177-188.

Sanner CA, Cunningham TJ, Goldberger ME (1994) NMDA receptor blockade rescues Clarke's and red nucleus neurons after spinal hemisection. J Neurosci 14:6472-6480.

Schnell L, Schneider R, Berman MA, Perry VH, Schwab ME (1997)
Lymphocyte recruitment following spinal cord injury in mice is altered by prior viral exposure. Eur J Neurosci 9:1000-1007.

Schwab ME, Bartholdi D (1996) Degeneration and regeneration of axons in the lesioned spinal cord. Physiol Rev 76:319-370.

Schwartz M, Moalem G, Leibowitz-Amit R, Cohen IR (1999) Innate and adaptive immune responses can be beneficial for CNS repair. Trends Neurosci 22:295-299.

Smolen AJ, Wright LL, Cunningham TJ (1983) Neuron numbers in the superior cervical sympathetic ganglion of rat: a critical comparison of methods for cell counting. J Neurocytol 12:739-750.

Streit WJ, Semple-Rowland SL, Hurley SD, Miller RC, Popovich PG, Stokes BT (1998) Cytokine mRNA profiles in contused spinal cord and axotomized facial nucleus suggest a beneficial role for inflammation and gliosis. Exp Neurol 152:74-87.

Strominger RN, McGiffen JE, Strominger NL (1987) Morphometric and experimental studies of the red nucleus in the albino rat. Anat Rec 219:420-428.

Wang XM, Terman JR, Martin GF (1998) Regeneration of supraspinal axons after transection of the thoracic spinal cord in the developing opossum, Didelphis virginiana. J Comp Neurol 398:83-97.

Yoles E, Schwartz M (1998) Degeneration of spared axons following partial white matter lesion: implications for optic nerve neuropathies. Exp Neurol 153:1-7.

Yong C, Arnold PM, Zoubine MN, Citron BA, Watanabe I, Berman ME, Festoff BW (1998) Apoptosis in cellular compartments of rat spinal cord after severe contusion injury. J Neurotrama 15:459-472.

Young W (1996) Spinal cord regeneration. Science 273:451. 